\title{
The effect of atmospheric and topographic correction methods on land cover classification accuracy
}

\author{
Steven Vanonckelen ${ }^{1 *}$, Stefaan Lhermitte ${ }^{2}$ and Anton Van Rompaey ${ }^{1}$ \\ ${ }^{1}$ Division of Geography, Katholieke Universiteit Leuven, Celestijnenlaan 200E, BE-3001 Heverlee, Belgium \\ ${ }^{2}$ Royal Netherlands Meteorological Institute, Wilhelminalaan 10, AE-3730 De Bilt, the Netherlands \\ *Corresponding author: Steven Vanonckelen. E-mail address: steven.vanonckelen@ees.kuleuven.be. Tel. + 32 16 329763.
}

\begin{abstract}
Mapping of vegetation in mountain areas based on remote sensing is obstructed by atmospheric and topographic distortions. A variety of atmospheric and topographic correction methods has been proposed to minimize atmospheric and topographic effects and should in principle lead to a better land cover classification. Only a limited number of atmospheric and topographic combinations has been tested and the effect on class accuracy and on different illumination conditions is not yet researched extensively. The purpose of this study was to evaluate the effect of coupled correction methods on land cover classification accuracy. Therefore, all combinations of three atmospheric (no atmospheric correction, dark object subtraction and correction based on transmittance functions) and five topographic corrections (no topographic correction, band ratioing, cosine correction, pixelbased Minnaert and pixel-based C-correction) were applied on two acquisitions (2009 and 2010) of a Landsat image in the Romanian Carpathian mountains. The accuracies of the fifteen resulting land cover maps were evaluated statistically based on two validation sets: a random validation set and a validation subset containing pixels present in the difference area between the uncorrected classification and one of the fourteen corrected classifications. New insights into the differences in classification accuracy were obtained. First, results showed that all corrected images resulted in higher overall classification accuracies than the uncorrected images. The highest accuracy for the full validation set was achieved after combination of an atmospheric correction based on transmittance functions and a pixel-based Minnaert topographic correction. Secondly, class accuracies of especially the coniferous and mixed forest classes were enhanced after correction. There was only a minor improvement for the other land cover classes (broadleaved forest, bare soil, grass and water). This was explained by the position of different land cover types in the landscape. Finally, coupled correction methods showed most efficient on weakly illuminated slopes. After correction, accuracies in the low illumination zone ( $\cos \theta \leq 0.65$ ) were improved more than in the moderate and high illumination zones. Considering all results, best overall classification results were achieved after combination of the transmittance function correction with pixel-based Minnaert or pixel-based Ctopographic correction. Furthermore, results of this bi-temporal study indicated that the topographic component had a higher influence on classification accuracy than the atmospheric component and that it is worthwhile to invest in both atmospheric and topographic corrections in a multi-temporal study.
\end{abstract}

Keywords: land cover mapping; classification accuracy assessment; atmospheric correction; topographic correction; Landsat; mountain areas, bi-temporal.

\section{Introduction}

Assessing the rate and spatial pattern of land cover changes is challenging given the ruggedness and inaccessibility of mountain areas (Lambin and Geist, 2006). Remote sensing techniques are privileged monitoring tools and yet suffer from methodological challenges that need to be resolved by correction methods (Balthazar et al., 2012; Lhermitte et al., 2011). A typical image preprocessing includes sensor calibration, atmospheric and topographic correction and relative radiometric normalization (Vicente-Serrano et al., 2008). Remote sensing-based land cover mapping in mountain areas is especially affected by atmospheric and topographic effects on recorded sensor signals 
(Soenen et al., 2008). Topographic effects are caused by differences in illumination due to solar position at the moment of image acquisition and result in a variation in reflectance response for similar terrain features (Veraverbeke et al., 2010). During the past 10 years, several atmospheric correction (AC) and topographic correction (TC) methods have been evaluated individually. Table 1 summarizes the most commonly used correction methods. Some authors (Kobayashi and SangaNgoie, 2008; Richter, 1996; 1998) have evaluated the influence of an integrated AC and TC correction. The integrated methods that have been developed include a specific combination of an atmospheric and a topographic correction. In literature, though, only a limited number of coupled AC and TC corrections has been tested and described so far (Table 1). Nevertheless, at present, a systematic comparison of the performance of different coupled corrections on classification accuracy is lacking.

$$
\ll \text { TABLE } 1 \text { APPROXIMATELY HERE >> }
$$

Several authors examined the influence of atmospheric and/or topographic corrections on land cover classification in mountain regions. In Table 2, an overview of recent studies about the influence of different correction methods on classification accuracy is presented. Depending on the correction methods used, there was no improvement in classification accuracy (Blesius and Weirich, 2005; Zhang et al., 2011) or an increase in the overall classification accuracy (OA) up to $40 \%$ (Gitas and Devereux, 2006). Although, it is difficult to compare the studies since the input files and parameters are different: study areas, vegetation types, sensors, DEM's, AC and TC corrections. $<$ TABLE 2 APPROXIMATELY HERE >>

In order to allow a good comparison between the existing AC and TC methods, a systematical analysis is essential. The overall research question of this paper is the evaluation of the impact of fifteen coupled AC and TC corrections on the accuracy of bi-temporal land cover classifications in mountain areas. A land cover classification analysis is performed on the image outputs after implementation of fifteen AC and TC combinations. The selected atmospheric and topographic correction methods are commonly used and have a different degree of complexity. They differ from relatively straightforward to methods that require a large amount of data and computations. The study area is a Landsat- 5 Thematic Mapper (TM) image in the Romanian Carpathians. Four aspects of the overall research question are examined for two validation sets:

- Which AC and TC combinations result in the best overall classification accuracy?

- What is the influence of different AC and TC combinations on class accuracies?

- Does the influence of coupled corrections on overall classification accuracy vary under different illumination conditions?

- Does the influence of coupled corrections on classification accuracy vary under different atmospheric conditions?

These four aspects help us to conclude what the individual effect of the different $A C$ and TC components is on classification accuracy.

\section{Material and methods}

\subsection{Study area and data acquisition}

\subsubsection{Study area}

In order to address the research questions described above, a mountain study area of $915 \mathrm{~km}^{2}$ in the Romanian Carpathian mountains was selected (Fig. 1(a) and (b)). The study area consists of rugged terrain with an elevation varying between 690 and 2,540 m above mean sea level. It includes the Făgăraș mountains at the intersection between the counties Brașov, Sibiu and Argeș.

$$
\text { < FIGURE } 1 \text { APPROXIMATELY HERE } \gg>
$$


The dominant lithology of the Făgăraș mountains is crystalline rock with occasional occurrence of limestone. Major soils include Podzols in the mountain zone and Cambisols in the foothill zone (FAO/UNESCO, 1988). Three natural vegetation zones are present: a foothill zone with mixed and broadleaved forests between 250 and 1,500 m with Betula pendula, Carpinus betulus and Fagus silvatica (Fig. 2(a)); a mountain zone (1,500-2,200 m; Fig. 2(b) and (c)) with coniferous forests (e.g. Abies alba, Picea abies, Pinus mugo); and an alpine zone (>2,200 m; Fig. 2(d)) above the tree line dominated by Carex curvula, Festuca supine and Juncus trifidus (Enescu, 1996; Kuemmerle et al., 2008; Mihai et al., 2007). The majority of the land cover comprises forests as forestry has traditionally been an important component of the regional economy and a major source of rural income (Ioras and Abrudan, 2006). Forests provide important ecosystem services and they are being threatened by natural and human induced threats: bark-beetle infestations (Knorn et al., 2012), wind-throws (Anfodillo et al., 2008), extensive salvage logging after wind-throws (Macovei, 2009) and land restitutions (Kuemmerle, 2008).

$$
\text { << FIGURE } 2 \text { APPROXIMATELY HERE >> }
$$

\subsubsection{Satellite and elevation data}

The recent opening of the global Landsat archive by the United States Geological Survey (USGS) provides new opportunities to advanced land cover studies. The released archive of Landsat imagery is temporally and spatially extensive and freely available for download (Knudby et al., 2010). For this study, Landsat-5 TM images (path 183/row 28) with acquisition days July 24, 2009 and August 12, 2010 were selected (see white-outlined rectangle in Fig. 1(a)). In this paper, all analyses were performed on the six non-thermal bands: three visible $(0.45-0.52 \mu \mathrm{m}, 0.52-0.60 \mu \mathrm{m}$ and $0.63-0.69$ $\mu \mathrm{m})$ and three infrared bands $(0.76-0.90 \mu \mathrm{m}, 1.55-1.75 \mu \mathrm{m}$ and $2.08-2.35 \mu \mathrm{m})$. The images were orthorectified with precision terrain correction level L1T by the USGS. Clouds and cloud shadows were ignored since cloud coverage in the study area was below $1 \%$. The solar elevation angle at image capture was respectively $57.8^{\circ}$ and $53.8^{\circ}$ for the 2009 and 2010 images. This implies that southeast facing slopes receive a maximum in solar radiation. The difference between the atmospheric parameters of both images is explained in the methodology. The co-registered digital elevation model (DEM) used in this study is the space shuttle radar topography mission (SRTM; Slater et al., 2006) from CGIARCSI/NASA. The SRTM provides a high-quality DEM at resolution levels of 1 arc $\sec (30 \times 30 \mathrm{~m})$ in the U.S.A. or 3 arc sec $(90 \times 90 \mathrm{~m})$ worldwide (Rabus et al., 2003). For this study, the SRTM version 4.1 was resampled to a pixel size of $30 \times 30 \mathrm{~m}$ by means of a bicubic spline interpolation to match the geo-reference of the Landsat dataset. This resampling approach was preferred over the use of the ASTER GDEM, which is originally characterized by a worldwide $\sim 30 \times 30$ $\mathrm{m}$ resolution, but is more subject to artefacts such as stripes or cloud anomalies (Hirt et al., 2010; Van Ede, 2004).

\subsubsection{Ground Control Points (GCP's)}

GCP's for land cover training and validation were gathered through field visits and the analysis of high-resolution satellite imagery. Training data were gathered systematically over the total image in order to collect the spectral range of the different classes. Pixels were chosen not too close together in order to avoid spatial autocorrelation (Campbell, 1981; Labovitz and Masuoka, 1984). First, eightythree usable GCP's were recorded through transect walks in the study area during field visits in May 2010 and July 2011 (Fig. 1(b)). The dominant vegetation type and topographic information, such as slope and elevation, was recorded for each point. Secondly, since the number of field-registered points was insufficient to serve as training and validation data for image classification, extra land cover data were derived by a visual interpretation based on high-resolution satellite imagery (WorldView-2, 8 bands, $46 \mathrm{~cm}$ resolution, acquisition date October 13, 2010). On the basis of the WorldView-2 image and field expertise, 322 extra reference points were identified. In order to check whether the land cover types for the selected reference points in 2010-2011 were equal in 2009, two Landsat images from the same season and acquired around identical dates (July 24, 2009 and August 
$12,2010)$ we selected. Furthermore, the consistency of the land cover types throughout the years 2009-2011 was checked based on Google Earth.

$$
<\text { FIGURE } 3 \text { APPROXIMATELY HERE } \gg
$$

\subsection{Methodology}

Fig. 3. presents an overview of the applied methodology. After data acquisition, the input images are corrected by applying the fifteen combinations of AC and TC corrections (including scenarios without atmospheric and/or topographic correction). Secondly, each corrected image is classified. Thirdly, the land cover maps are evaluated by comparing overall classification accuracies, class accuracies and overall accuracies for three illumination conditions.

\subsubsection{Preprocessing steps}

The digital numbers (DN) of each spectral band were calibrated to at-satellite radiances $\left(L_{s, \lambda}\right.$, in $\mathrm{W} / \mathrm{m}^{2}$ sr $\mu \mathrm{m}$; Eq. (1)) based on gain and offset values obtained from the calibration file in the metadata (where $L_{s}$ refers to the at-satellite radiances and $\lambda$ to the band wavelength):

$$
L_{s, \lambda}=\mathrm{DN} \times \text { gain }+ \text { offset }
$$

The calibrated radiance values were atmospherically corrected by means of 3 different AC methods (including no AC) as shown in Table 3. The AC methods used in this study are the following: i) no AC; ii) dark object subtraction (DOS) correction and iii) correction based on transmittance functions (TF correction). The methods were selected based on their application and modeling complexity. DOS correction is a widely used and a relative straightforward atmospheric correction method. The approach calculates a minimum radiance value $\left(L_{p}\right.$, in $\left.\mathrm{W} / \mathrm{m}^{2} \mathrm{sr} \mu \mathrm{m}\right)$ for each band as the 1 th percentile radiance value over the image. $L_{p}$ accounts for the atmospheric effect and is subtracted from all pixels (Chavez, 1996; Eq. 3 in Table 3). The $L_{p}$ values (in W/ $\mathrm{m}^{2} \mathrm{sr} \mu \mathrm{m}$ ) per band for the 2009 and 2010 images are respectively: [37.50, 26.12, 14.50, 36.16, 2.76, 0.44] and [40.60, 27.57, 16.58, $44.92,3.60,0.57]$. The ambient atmospheric pressure $(P$, in mbar) is respectively 995 and 925 mbar for the 2009 and 2010 image. $P$ is obtained from daily mean surface pressures (ascending; in mbar) in NASA's atmospheric Giovanni portal (http://disc.sci.gsfc.nasa.gov/giovanni/overview/index.html, last accessed on January 8,2013$)$. The value of $P$ is obtained for the central point in the image and at acquisition time. Precipitable water vapor values $(W)$ are respectively 1.39 and $2.99 \mathrm{~cm}$ and obtained from the moderate-resolution imaging spectroradiometer (MODIS) on the Aqua satellite, as available on NASA's atmospheric Giovanni portal. The TF correction extends the DOS method with a denominator containing normalized and band specific transmittance functions of water-vapor absorption and Rayleigh scattering as described in Eq. 4, 5 and 6, and in the subscript of Table 3. After AC correction, the path radiance $\left(L_{t, \lambda}\right.$ in $\left.\mathrm{W} / \mathrm{m}^{2} \mathrm{sr} \mu \mathrm{m}\right)$ was converted to at-surface reflectance $\left(\rho_{T, \lambda}\right)$ using Eq. 2 described by Markham and Barker (1986).

$$
\rho_{T, \lambda}=\frac{\pi L_{t, \lambda} d^{2}}{E S U N_{\lambda} \cos \theta_{s}}
$$

where: $\rho_{T, \lambda}=$ observed surface reflectance on an inclined surface (\%); $L_{t, \lambda}=$ path radiance after atmospheric correction $\left(\mathrm{W} / \mathrm{m}^{2} \mathrm{sr} \mu \mathrm{m}\right) ; d=$ earth-sun distance (astronomical units); $\vartheta_{s}=$ solar zenith angle (degrees) and $E S U N_{\lambda}=$ mean exo-atmospheric solar irradiance $\left(\mathrm{W} / \mathrm{m}^{2} \mu \mathrm{m}\right)$ according to the Landsat 5 sensor values of Chander et al. (2009) $\left(E S U N=\left[1983,1796,1536,1031,220,83 \mathrm{~W} / \mathrm{m}^{2}\right.\right.$ $\mu \mathrm{m}))$. In a final step, the normalized reflectance of a horizontal surface $\left(\rho_{H, \lambda}\right)$ was calculated using five topographic corrections described in Table 3 and including the case of no TC. The five selected TC methods were the following: i) no TC, ii) band ratioing, iii) cosine correction, iv) pixel-based Minnaert correction (PBM) and v) pixel-based C-correction (PBC). These TC methods were chosen to test different techniques that are commonly used and that have an increasing requirement of input parameters. Band ratioing is based on the assumption that reflectance values vary proportionally in 
all bands. The method divides the observed reflectance by the arithmetic mean of observed reflectances over all spectral bands (Eq. 7, Table 3). The cosine correction reconstructs the differential illumination on the basis of the incident solar angle 6 that is the angle between the ground surface and the solar zenith direction (Eq. 8, Table 3). An alternative DEM-based approach that accounts for non-Lambertian behavior of reflectance by means of an empirical Minnaert constant $\mathrm{k}$ is the Minnaert correction. Different procedures for the calibration of the k-value have been proposed and in this study the method of Lu et al. (2008) is implemented (Eq. 9, Table 3). The pixel-based C-correction (Eq. 10, Table 3) consists of the topographic part of the integrated radiometric correction of Kobayashi and Sanga-Ngoie (2008). This method implements an additional factor $C_{\lambda}$ to the cosine correction to account for diffuse sky irradiance. In general, the three $A C$ and five TC methods - including no AC and no TC - were coupled to fifteen different combinations of AC and TC methods. The combination of no topographic and no atmospheric correction was considered as the baseline scenario. The most complex coupled correction (TF-PBM) simulated the total radiance pathway through the atmosphere and implemented the path radiance, solar direct irradiance, sky diffuse irradiance and adjacent terrain reflectance. Finally, the uncorrected images and the fourteen corrected images provide the input for the classification protocol described below.

< TABLE 3 APPROXIMATELY HERE >>

\subsubsection{Land cover classification}

In order to obtain classification accuracies, an appropriate classification algorithm is required. When detailed information of the study area exists and good training data are available, a supervised classification is preferable (Kuemmerle et al., 2006). The supervised maximum likelihood (ML) classifier based on the Gaussian distribution of the elements in the coherent scattering matrix is used in this study (Foody, 2002). The maximum likelihood decision rule is relatively convenient to implement when sufficient GCP's are available. It is at present still the most widely applied classification technique because of its relative simplicity and robustness (Gao and Zhang, 2009). Furthermore, the classifier utilizes means, variances and covariances of training site statistics, where most other decision rules are based on simpler statistics (Chen et al., 2004). Table 2 shows moreover that ML classification is still being most commonly implemented in recent studies on land cover accuracy assessment (e.g. Gao and Zhang, 2009; Soenen et al., 2008). The classification procedure is based on a 10-fold cross validation (Kohavi, 1995) where the image is repeatedly trained with twothirds of the reference points and validation is based on 10-fold cross validation with the remaining one-third of reference points. Thereby, the 405 reference points are repeatedly and randomly subdivided in training and validation datasets. First, the classification is performed on the uncorrected and corrected images of 2010. Secondly, the endmembers of the 2009 image are collected based on the GCP's of the 2010 image and applied on the 2009 image. The land cover classes used for image classification are described in Table 4. In total, six classes are discerned, including two non-vegetation classes (bare soil and water surface). Average reflectance values per wavelength and land cover type for the uncorrected images and the most advanced method (TFPBM) of 2009 (solid line) and 2010 (dashed line) are also analyzed to understand the differences in accuracy.

$$
\ll \text { TABLE } 4 \text { APPROXIMATELY HERE } \gg>
$$

\subsubsection{Evaluation of land cover classification}

The performance of land cover classification maps for each of the correction methods is examined based on three statistical analyses:

(1) Overall classification accuracy to determine the best combination of AC and TC;

(2) Land cover class accuracies to understand the effect on each class;

(3) Classification accuracies to examine the effect of different illumination conditions. 
One of the most popular measures of classification accuracy derived from the confusion matrix is the percentage of cases correctly allocated (Foody, 2002). A problem is that some cases are allocated to the correct class purely by chance (Congalton, 1991; Pontius, 2000; Rosenfield \& Fitzpatrick-Lins, 1986; Turk, 1979). To accommodate for the effects of chance agreement, Cohen's kappa coefficient has often been used and some commentators argue that it should, in some circumstances, be adopted as a standard measure of classification accuracy (Cohen, 1960; Congalton et al., 1983; Foody, 2002; Smits et al., 1999). In this study, average kappa coefficients of the 2009 and 2010 images are derived as a measure of classification accuracy. The range of classification accuracies between both dates is shown through the whiskers on the bars and illustrates the difference in accuracy between the two dates. In this context, two validation datasets are used: a set containing all validation pixels and a so called difference subset. This subset includes the validation pixels that are classified differently between the classification of one of the coupled corrections and the classification of the uncorrected image. At class level, differences of average 2009-2010 kappa values ( $\delta$ kappa) for each class are calculated using the following equation (Zhang et al., 2011):

$$
\delta \mathrm{kappa}_{i}=\mathrm{kappa}_{i} \text {, corrected }-\mathrm{kappa}_{i} \text {, uncorrected }
$$

where: $k a p p a a_{i}$ corrected is the kappa value of class $i$ based on a corrected image classification; and kappa $_{i \text {, uncorrected }}$ is the kappa value of class $i$ derived from the uncorrected image classification. In this section, the global $\delta$ kappa over all fourteen correction methods is also calculated to provide a general perspective on the performance of all coupled corrections. In general, topographic correction has a lower impact on the classification accuracy on flatter terrain. Therefore, the effect of AC/TC methods on classification accuracy is evaluated for three different levels of illumination separately. Therefore, both validation sets are divided in three illumination zones based on the illumination parameter $\cos B$ that is calculated using Equation 12 and varies between -1 and +1 (maximum illumination) (Civco, 1989):

$$
\cos \theta=\cos \vartheta_{s} \cos \vartheta_{n}+\sin \vartheta_{s} \sin \vartheta_{n} \cos \left(\phi_{t}-\phi_{a}\right)
$$

The three illumination zones are: low illumination [ $\cos \theta \leq 0.65]$, moderate illumination $[0.65<\cos \theta$ $<0.85$ ], and high illumination [ $\cos B \geq 0.85$ ]. The spatial distribution of each zone is illustrated in Fig. 4. An equal area subdivision of one-third of the total area is approximated with these class boundaries. Finally, based on all accuracy criteria, the individual effect of the two components (AC and TC) within a coupled correction is evaluated and the influence of coupled corrections under different atmospheric conditions is examined.

$$
<<\text { FIGURE } 4 \text { APPROXIMATELY HERE } \gg>
$$

\section{Results}

\subsection{Class reflectance}

Figure 5 shows average reflectance values per wavelength and land cover type for a) the uncorrected images and b) after TF-PBM correction of 2009 (solid line) and 2010 (dashed line). The spectra for all land cover types of both dates before correction are overlapping (Fig. 5(a)). Therefore, it is difficult to differentiate land cover classes in all bands before correction. On the contrary, the different land cover spectra of all bands show less overlap after TF-PBM correction. In band 1, 2, 3 and 7, the reflectance values per land cover class are less corresponding and the overlap between land cover classes also diminishes for bands 4 and 5 . Especially the reflectance values of the GRASS, BL and WT classes are easily to differentiate after correction because of a strong overlap between the reflectance values of both dates. There is also an improvement between the differentiation of the three other land cover classes: the reflectance values between both dates are more similar or the values between the different land cover types are less corresponding. 


\subsection{Overall accuracy}

Fig. 6 presents average 2009-2010 kappa values of the uncorrected and corrected classifications using the full validation set (black) and the difference subset (white). For the full validation set, average kappa coefficients are generally high, varying between 0.87 (no AC and no TC; range 0.017) and 0.94 (TF-PBM; range 0.023). In this study, all coupled corrections result in higher average kappa values. The land cover maps of methods that combine an atmospheric correction (DOS or TF) with a PBC or PBM topographic method are performing best. For these combinations, average kappa values are 0.94 (Fig. 6; range respectively 0.006 and 0.007). Application of an atmospheric correction (DOS or TF) without TC correction increased average value with respectively 0.03 and 0.04 for the full validation set. Implementation of topographic corrections without AC correction resulted in higher average kappa values: +0.008 for band ratio, +0.015 for cosine, +0.027 for PBC and +0.022 for PBM correction. The range of classification accuracies provides information of the difference in classification accuracy between the 2009 and 2010 classification. For the coupled corrections without AC, the average range of classification accuracy between both dates is larger ( $\sim 0.017)$ than for the DOS ( 0.015) and TF $(\sim 0.007)$ corrections respectively. This implies that the difference in classification accuracy between different dates is larger when no AC is applied, whereas it is smallest for TF corrections with the TF-PBC method performing best (range 0.006).

A new approach in this study was the analogue analysis that was carried out on the difference pixels. The implementation of a so-called 'difference subset of pixels' had the major advantage that differences in accuracies and ranges were more pronounced. The white bars in Fig. 6 show average kappa values in the difference area. The average kappa value of the uncorrected image in the difference area (0.22; range 0.025$)$ is lower than the value of the entire image (0.87; range 0.017$)$. Increases in average kappa value after application of topographic corrections without AC correction were the following: 0.10 for band ratio, 0.19 for cosine, and 0.23 for PBC and PBM correction. Implementation of DOS and TF without TC correction led to average kappa increases of respectively 0.13 and 0.20 for the difference subset. The highest average kappa values in the difference area with lowest range are achieved after implementation of TF-PBC correction (average 0.77; range 0.012) and TF-PBM correction (average 0.76; range 0.023).

\section{< FIGURE 6 APPROXIMATELY HERE >>}

To illustrate the effect of the different combinations, outputs of three representative techniques are shown for the 2009 land cover maps in Fig 7: the baseline scenario (i.e., the uncorrected image), a combination with a low classification accuracy (i.e., a TF and cosine combination) and a scenario with high accuracy (i.e., a TF and PBC combination). Figure 76(a)-(c) show the resulting true color composites and classified images. The difference in illumination is clearly visible for points 1 and 2 in the composite without correction (Fig. 7(a)) and combination of TF and cosine correction causes overcorrection in the visible bands (Fig. 7(b)). The TF-PBC correction (Fig. 7(c)) reduces the differential illumination effects: the same land cover types have comparable spectral values for similar terrain features on opposite facing slopes. As a result, illumination differences between points 1 and 2 in Fig. 7(c) on opposite facing slopes have disappeared. The classification results show no clear differences between land cover maps resulting from the uncorrected (Fig. 7(a)) and the TFcosine corrected image (Fig. 7(b)). Table 5 shows the percentages of 2009 LC classes for the three combinations of correction methods and confirms this finding. There is only a minor difference of $\pm 3 \%$ in the broadleaved and mixed forest class that is hardly to distinguish on the indicated points 3 and 4 in Figs. 7(a) and (b). Compared to these two maps, the LC map resulting from TF-PBC correction shows less BL and MX forest (Fig. 7(c)). This is confirmed by the data in Table 5: the decrease in the $\mathrm{BL}$ and $\mathrm{MX}$ classes after TF-PBC correction and compared to the baseline scenario is respectively $7 \%$ and $12 \%$. The BS class is decreasing with $3 \%$ and in contrast, the CF and GRASS classes are increasing with respectively $8 \%$ and $14 \%$. The difference is also shown by comparison between points 3 and 4 
on the LC maps. For point 3, the MX forest type in Figs. 7(a) and (b) has disappeared and is replaced by $\mathrm{CF}$ forest in Fig. 7 (c). The dominant $\mathrm{BL}$ forest type in point 4 is replaced by grasslands and bare soil in Fig. 7(c).

$$
\begin{aligned}
& <<\text { TABLE } 5 \text { APPROXIMATELY HERE } \gg> \\
& <<\text { FIGURE } 7 \text { APPROXIMATELY HERE }>
\end{aligned}
$$

\subsection{Class accuracy}

Fig. 8 shows average 2009-2010 $\delta$ kappa values per class between uncorrected and corrected image using the full validation set for the 14 combinations of corrections and a global value per class over the 14 combinations of corrections. The results are included in a bubble chart whereby the size of the bubble represents the average 2009-2010 $\delta$ kappa value. A red color represents a negative $\delta$ kappa value and a blue color a positive $\delta$ kappa value. Positive average $\delta$ kappa values indicate a more accurate classification of a specific land cover class compared to the baseline scenario. The results show positive average $\delta$ kappa values for the CF and MX classes which implies that coupled corrections improve classification accuracy for these LC categories. The combination of TF-PBM correction produces the best results: increases in average kappa values of respectively 0.17 and 0.18 for the CF and MX forest types. The global $\delta$ kappa values over all fourteen correction methods are also shown in Figure 8. The global value increases with 0.09 for the $\mathrm{CF}$ and $\mathrm{MX}$ forest types and with 0.01 for the GRASS class. For the three other LC types (BS, BL and WT), general mapping accuracy is not increasing after correction: difference values of the WT and BL class have not been changed and there is even a small negative global $\delta$ kappa value $(-0.03)$ for the BS class.

$$
<<\text { FIGURE } 8 \text { APPROXIMATELY HERE >> }
$$

The average 2009-2010 accuracy of the six classes is also evaluated within the difference area (Fig. 9). Average $\delta$ kappa values of the CF and MX forest types are especially improving after correction. The trend for the $\mathrm{CF}$ and $\mathrm{MX}$ forest class is similar as the trend for the full validation set but almost all average $\delta$ kappa values have increased. The maximum average $\delta$ kappa value for the CF class is 0.30 (TF-PBC combination), compared to the maximum average value of 0.17 for the CF class using the full validation set. The MX forest class has a maximum average $\delta$ kappa value of 0.20 (TF-PBM combination), an increase with 0.02 compared to the maximum average value of 0.18 for the full validation set. Trends for the other classes are not uniform. The global $\delta$ kappa values (Fig. 9) over all fourteen correction methods per LC class are pinpointing to general increases of respectively 0.19 and 0.10 for the CF and MX forest types. For the four other LC types (BS, BL, GRASS and WT), global $\delta$ kappa values are not increasing or even slightly decreasing in the difference zone. Compared to the full validation set, BS and GRASS classes are performing slightly worse in the difference zone (global $\delta$ kappa of -0.01). The global class accuracy of WT is slightly positive (0.01) and the BL class is performing equal before and after correction.

$$
<<\text { FIGURE } 9 \text { APPROXIMATELY HERE >> }
$$

\subsection{Illumination conditions}

Figure 10 shows that the average 2009-2010 accuracy of the uncorrected image is small in the low illumination zone (kappa value of 0.23 ; range 0.018 ). After correction the accuracy is improving, especially for the combination of TF-PBC or TF-PBM. For those two combinations, average kappa values are increasing from 0.23 (range 0.018 ) to 0.72 (range respectively 0.011 and 0.012 ). The range of classification accuracies between both dates is smallest after implementation of the TF with a topographic correction method: 0.013 (band ratioing), 0.014 (DOS), 0.011 (PBC) and 0.012 (PBM). Results in the difference area of the low illumination zone show again that highest average kappa values with lowest range are achieved after implementation of TF-PBC (average 0.72; range 0.011) and TF-PBM correction (average 0.72; range 0.012 ). The same trends are visible in the moderate and high illumination zone. Here, the accuracies are also improving, although the increases are smaller 
(respectively +0.45 and +0.42 between no AC/TC and TF-PBM) than in the low illumination zone (+0.49 between no AC/TC and TF-PBM). In the moderate zone, the largest improvement in accuracy is an increase in average kappa from 0.33 (baseline scenario; range 0.015) to 0.84 (TF-PBM; range 0.007). Overall, the accuracy is largest in the high illumination zone with average kappa value of 0.85 for the TF-PBM combination (range 0.007).

$$
\text { <<FIGURE } 10 \text { APPROXIMATELY HERE >> }
$$

\section{Discussion}

This study provided new insights on the impact of fourteen combinations of atmospheric and topographic correction methods on the accuracy of land cover classification. Adding and comparing the effect of AC/TC correction in combination with different classification algorithms would generate so many data and to some extent hide the single effect of AC/TC correction. Therefore, the maximum likelihood decision rule was applied since it's still the most widely applied classification technique and accurate when sufficient GCP's are available. The GCP's were recorded through transect walks during field visits in May 2010 and July 2011 and applied on both dates. Optimally, GCP's of 2009 were also available. The land cover classification under the baseline scenario (no topographic and no atmospheric corrections) was relatively high because of the high quality of the Landsat image and the availability of a large number of land cover calibration data that were collected during fieldwork.

Differentiation between land cover classes was relatively difficult before correction: there was an overlap between average reflectance values of both dates per land cover type and band and the differences between average class reflectance values was small (Figure 5(a)). Average reflectance values per wavelength and land cover type before and after correction showed that the differentiation between land cover classes simplified after coupled correction. Considering overall accuracies of the full validation set, average kappa values were generally high. The overall high accuracies were achieved through the implementation of a high-quality image and a high number of reference data sampled on the ground by means of field work.

The results indicated that average land cover classification accuracy increased more after coupled AC/TC correction than when an individual AC or TC correction is applied. The average kappa coefficients varied between 0.87 for the baseline scenario and 0.94 for TF-PBM correction. Compared to other studies performed by Hale and Rock (2003), Gitas and Devereux (2004) and Cuo et al. (2010), overall accuracies were high and the increases in accuracy were therefore lower. Comparable results were achieved by a study of Huang et al. (2008). There, overall accuracy increased from $85.5 \%$ to $89.7 \%$ after a combination of a MODTRAN and SCS correction. Gao and Zhang (2009) described an OA increase from $51 \%$ to $91 \%$ after a simplified normalization. The characteristics of the study area (steep slopes, no intensive human influence, few roads and low population) were favorable to discourage large changes in land cover between both dates. Although, a small variety in accuracy range between both dates was expected since there were changes between the on ground land cover types of 2009 and 2010. The range in classification accuracy between both dates was larger when no AC was applied (0.017), whereas the range was smallest for TF corrections (0.007). The ranges for the accuracies after DOS ( 0.015) and no AC were comparable ( 0.017), but a larger variability in range for DOS correction was normally expected since the overall accuracies were higher after DOS correction. A large range in accuracies of land cover maps without AC correction was found since the atmospheric parameters between both images were different. After AC and TC correction, there was a smaller range in accuracies because the effect of diverse atmospheres and illumination was removed. Therefore, an identical and optimal classification was performed after coupled AC/TC correction. In general, the TF-PBC method was performing best with a range of only 0.006 .

The composite without correction (Fig. 7(a)) showed differences in illumination on opposite slopes. Combination of TF and cosine correction (Fig. 7(b)) caused an overcorrection in the visible bands. This 
was explained by the ignorance of the diffuse sky irradiance, resulting in an overestimation of the output radiance data (Teillet et al., 1982). Combination of the TF-PBC and TF-PBM correction (Fig. $7(c)$ ) reduced the differential illumination effects on opposite facing slopes and solved the problem of overcorrection. The natural catena from broadleaved forest on the footslopes over mixed and coniferous forest to grasslands at the highest altitudes (as described in the study area section) was best depicted on the TF-PBC map. This result was explained by the location of the different land cover types in the landscape: the forest classes (BL, MX and CF) covered the steepest slopes dominated by differences in illumination (Fig. 1(a)-(c)). On the contrary, the other land cover types (BS, GRASS and WT) were located on the mountain ridge where illumination was high. As a consequence, it was harder to improve the differentiation between these three land cover classes since the class accuracy before correction was already high. In less mountainous areas and when atmospheric variables between the dates are larger, atmospheric corrections have a larger impact on classification accuracy. Therefore, it is recommended to invest in AC and TC methods for multitemporal studies. A balance must be found between the benefits of AC/TC correction in terms of increased classification accuracy and decreased automation potential. Such balance depends on: the size of the study area, the number of footprints, the number and the location of the available GCP's, the location and the spectral signatures of the land cover types that need to be mapped.

The results of the class accuracies showed positive average $\delta$ kappa values for CF and MX classes and no real classification improvements for the other land cover classes (BS, BL, GRASS and WT). The study of Zhang et al. (2011) at class level showed that $\delta$ kappa values of pine forests on sunny and shaded slopes increased by a maximum of about 0.12 using topographically corrected images. On the contrary, $\delta$ kappa values of oak and mixed forests on sunny and shaded slopes decreased up to 0.7 after correction. The MFM-TOPO correction of Soenen et al. (2008) increased pine class accuracy by $62 \%$ over shaded slopes and spruce class accuracy by $13 \%$ over moderate slopes. Finally, classification accuracies were evaluated for three illumination conditions separately. Here, new insights were obtained on the effect of different illumination zones within the difference area. Average accuracy of the uncorrected image was smallest in the low illumination zone and largest in the high illumination zone. The largest improvements in accuracy were achieved in the low illumination zone, where the average kappa value increased from 0.23 (baseline scenario; range 0.018 ) to 0.73 (TF-PBM; range 0.012). This comparison showed that the correction methods performed best on steep slopes in mountain areas.

Considering the overall results, the study showed that the most complex coupled corrections (TF-PBC and TF-PBM) performed best because they simulate the radiance pathway through the atmosphere in the most accurate way. In general, results indicated that the topographic component had a higher influence on classification accuracy than the atmospheric component. This is shown by the difference in overall classification accuracies in Figure 6 for the full and difference subset. The accuracy differences are explained by relative large differences in elevation (690 to 2,540 m above mean sea level) and solar elevation angles (respectively $57.8^{\circ}$ and $53.8^{\circ}$ ) between both dates. There are relative small differences in atmospheric parameters (minimum radiance, ambient atmospheric pressure and precipitable water vapor) as described in the preprocessing steps section. In a multi-temporal study with more pronounced variations in atmospheric parameters, the impact AC methods becomes more important.

\section{Conclusions}

A wide range of atmospheric and topographic correction methodologies is available in literature. The application of coupled corrections is labor and data intensive, especially for the most advanced techniques. It is therefore important to examine the added value of these corrections on land cover classification. In this paper, the added value of fifteen coupled corrections (including the scenarios without atmospheric and/or topographic correction) was evaluated on a bi-temporal dataset and based on 3 criteria: overall classification accuracy, class accuracy and illumination specific accuracy. 
The statistical analysis was performed for two validation sets: a set containing all validation pixels and a subset containing the difference pixels between the classified, uncorrected image and one of the classified, corrected images.

Analysis of average reflectance values per wavelength and land cover type between the uncorrected and corrected images of 2009 and 2010 show that differentiation between all land cover classes improves after coupled correction. The accuracy results show that overall classification accuracies of all corrected land cover maps increase after coupled correction. Average kappa coefficients for the full validation sets differ between 0.87 for the scenario without corrections (range 0.017) and 0.94 for the atmospheric correction based on transmittance functions (TF) coupled with the pixel-based Minnaert (PBM) correction (range 0.023). Higher increases in average kappa values are present for all coupled corrections when the difference validation subset is used. The results also indicate that average land cover classification accuracy increases more after coupled AC/TC correction than after an individual AC or TC correction. After coupled AC/TC correction, the differences in range between both dates and images are removed and an identical and optimal classification is performed. Results of the class accuracies show positive average $\delta$ kappa values for coniferous and mixed classes and no real classification improvements for the four other land cover classes. In this study, the impact of coupled AC/TC corrections is especially effective to increase the mapping accuracy of the different forest types. AC/TC corrections are less effective in increasing mapping accuracies of land cover types above the tree line since these area's are well illuminated. Considering the analysis in the different illumination zones, coupled correction methods perform best in the low illuminated areas.

In this bi-temporal study, results indicate that the influence of the topographic component on classification accuracy is higher than the atmospheric component. This is explained by relative small variations in atmospheric parameters and relative large differences in topographic parameters between both dates. Although the topographic component influences the accuracy more than the atmospheric component, it is worthwhile to invest in both atmospheric and topographic corrections in a multi-temporal study. For each application a balance must be found between the benefits of $A C$ and TC corrections in terms of increased classification accuracy and decreased automation potential of the preprocessing procedure. Furthermore, application of a coupled correction based on a complex TC component (PBC or PBM) and a TF atmospheric component is justified in this study. Best overall classification results are achieved after TF-PBM or TF-PBC because the pathway through the atmosphere is simulated in the most accurate way. Drawback of these advanced methods are, however, their data requirements that do not allow a fully automated application and integration in image preprocessing chains. Further research should focus on the application of the coupled corrections to other study sites and larger temporal series.

\section{Acknowledgements}

This research was funded by the Belgian Science Policy, Research Program for Earth Observation Stereo II, contract SR/00/133, as part of the FOMO project (remote sensing of the forest transition and its ecosystem impacts in mountain environments). The work done by the anonymous referees is greatly acknowledged, their comments and suggestions significantly improved this manuscript.

\section{References}

Anfodillo, T., Carrer, M., Valle, E.D., Giacoma, E., Lamedica, S., Pettenella, D., 2008. Current State of Forest Resources in the Carpathians. Activity 2.7: Forestry and timber industry. Università Degli Studi Di Padova, Dipartimento Territorio e Sistemi Agro-Forestali, Legnaro. 
Balthazar, V., Vanacker, V., Lambin, E.F., 2012. Evaluation and parameterization of ATCOR3 topographic correction method for forest cover mapping in mountain areas. International Journal of Applied Earth Observation and Geoinformation 18, 436-450.

Berk, A., Bernstein, L.S., Anderson, G.P., Robertson, D.C., Chetwynd, J.H., Adler-Golden, S.M., 1998. MODTRAN Cloud and multiple scattering upgrades with application to AVIRIS. Remote Sensing of Environment 65, 367-375.

Bishop, M.P., Colby, J.D., 2002. Anisotropic reflectance correction of SPOT-3 HRV imagery. International Journal of Remote Sensing 23, 2125-2131.

Bishop, M.P., Shroder, J.F., Colby, J.D, 2003. Remote sensing and geomorphometry for studying relief production in high mountains. Geomorphology 55, 345-361.

Blesius, L., Weirich, F., 2005. The use of the Minnaert correction for land-cover classification in mountainous terrain. International Journal of Remote Sensing 26, 3831-3851.

Campbell, J.B., 1981. Spatial correlation effects upon accuracy of supervised classification of land cover. Photogrammetric Engineering Remote Sensing 47, 355-363.

Chander, G., Markham, B.L., Helder, D.L., 2009. Summary of current radiometric calibration coefficients for Landsat MSS, TM, ETM and EO-1 ALI sensors. Remote Sensing of Environment 113, 893-903.

Chavez, P.S., 1996. Image-based atmospheric correction-revisited and improved. Photogrammetric Engineering and Remote Sensing 62, 1025-1036.

Chen, D. Stow, D.A., Gong, P., 2004. Examining the effect of spatial resolution and texture window size on classification accuracy: an urban environment case. International Journal of Remote Sensing 25, 2177-2192.

Civco, D.L., 1989. Topographic normalization of Landsat Thematic Mapper digital imagery. Photogrammetric Engineering and Remote Sensing 55, 1303-1309.

Coburn, C.A., Roberts, A.C.B., 2004. A multiscale texture analysis procedure for improved forest stand classification. International Journal of Remote Sensing 25, 4287-4308.

Cohen, J., 1960. A coefficient of agreement for nominal scales. Educational and Psychological Measurement 20, 37-46.

Colby, J.D., 1991. Topographic normalization in rugged terrain. Photogrammetric Engineering and Remote Sensing 57, 531-537.

Conese, C., Gilabert, M.A., Maselli, F., Bottai, L., 1993. Topographic normalization of TM scenes through the use of an atmospheric correction method and digital terrain models. Photogrammetric Engineering and Remote Sensing 59, 1745-1753.

Congalton, R.G., 1991. A review of assessing the accuracy of classifications of remotely sensed data. Remote Sensing of Environment 37, 35-46. 
Congalton, R.G., Oderwald, R.G., Mead, R.A., 1983. Assessing Landsat classification accuracy using discrete multivariate analysis statistical techniques. American Society of Photogrammetry 49, 16711678.

Cuo, L., Vogler, J.B., Fox, J.M., 2010. Topographic normalization for improving vegetation classification in a mountainous watershed in Northern Thailand. International Journal of Remote Sensing 31, 3037-3050.

Ekstrand, S., 1996. Landsat TM-based forest damage assessment: correction for topographic effects. Photogrammetric Engineering and Remote Sensing 62, 151-161.

Enescu, V., 1996. Forest genetic resources conservation in Romania. Food And Agriculture Organization of the United Nations (FAO), Rome.

FAO/UNESCO, 1988. Soil Map of the World, Revised Legend. World Soil Resources, Rome.

Foody, G.M., 2002. Status of land cover classification accuracy assessment. Remote Sensing of Environment 80, 185-201.

Gao, Y., Zhang, W., 2009. A simple empirical topographic correction method for ETM+ imagery. International Journal of Remote Sensing 30, 2259-2275.

Gilabert, M.A., Conese, C., Maselli, F,. 1994. An atmospheric correction method for the automatic retrieval of surface reflectances from TM images. International Journal of Remote Sensing 15, 20652086.

Gitas, I.Z., Devereux, B.J., 2006. The role of topographic correction in mapping recently burned Mediterranean forest areas from Landsat TM images. International Journal of Remote Sensing 27, 41-54.

Gu, D., Gillespie, A., 1998. Topographic normalization of Landsat TM images of forest based on subpixel sun-canopy-sensor geometry. Remote Sensing of Environment 64, 166-175.

Hale, S.R., Rock, B.N., 2003. Impact of topographic normalization on land-cover classification accuracy. Photogrammetric Engineering and Remote Sensing 69, 785-791.

Hantson, S., Chuvieco, E., 2011. Evaluation of different topographic correction methods for Landsat imagery. International Journal of Applied Earth Observation and Geoinformation 13, 691-700.

Hirt, C., Filmer, M.S., Featherstone, W.E., 2010. Comparison and validation of the recent freelyavailable ASTER GDEM ver1, SRTM ver4.1 and GEODATA DEM-9S ver3 digital elevation models over Australia. Australian Journal of Earth Sciences 57, 337-347.

Huang, H., Gong, P. Clinton, N., Hui, F,. 2008. Reduction of atmospheric and topographic effect on Landsat TM data for forest classification. International Journal of Remote Sensing 29, 5623-5642.

Ioras, F., Abrudan, I.V., 2006. The Romanian forestry sector: privatization facts. International Forestry Review 8, 361-367.

Jensen, J.R., 1996. Introduction digital image processing: a remote sensing perspective, third ed. Prentice-Hall, Englewood Cliffs, New Jersey. 
Kneizys, F.X., Shettle, E.P., Abreu, L.W., Chetwynd, J.H., Anderson, G.P., Gallery, W.O., Selby, J.E.A., Clough, S.A., 1988. User's Guide to LOWTRAN-7, Air Force Geophysics Laboratory, Hanscom, Massachusetts.

Knorn, J., Kuemmerle, T., Radeloff, V.C., Szabo, A., Mindrescu, M., Keeton, W.S., Abrudan, I., Griffiths, P., Gancz, V., Hostert, P., 2012. Forest restitution and protected area effectiveness in post-socialist Romania. Biological Conservation 146, 204-212.

Knudby, A., Newman, C., Shaghude, Y., Muhando, C., 2010. Simple and effective monitoring of historic changes in nearshore environments using the free archive of Landsat imagery. International Journal of Applied Earth Observation and Geoinformation 12, S116-S122.

Kobayashi, S., Sanga-Ngoie, K., 2008. The integrated radiometric correction of optical remote sensing imageries. International Journal of Remote Sensing 29, 5957-5985.

Kohavi, R., 1995. A study of cross-validation and bootstrap for accuracy estimation and model selection. Proceedings of the 14th international joint conference on artificial intelligence 2, 11371143.

Kuemmerle, T., Müller, D., Griffiths, P., Rusu, M., 2008. Land use change in Southern Romania after the collapse of socialism. Regional Environmental Change 9, 1-12.

Kuemmerle, T., Radeloff, V.C., Perzanowski, K., Hostert, P., 2006. Cross-border comparison of land cover and landscape pattern in Eastern Europe using a hybrid classification technique. Remote Sensing of Environment 103, 449-464.

Labovitz, M.L., Masuoka E.J., 1984. The influence of autocorrelation in signature extraction:an example from a geobotanical investigation of Cotter Basin, Montana. International Journal of Remote Sensing 5, 315-332.

Lambin, E.F., Geist, H.J., 2006. Land use and land cover change, local processes and global impacts, third ed. Springer-Verlag, Heidelberg, Berlin, New York.

Lenot, X., Achard, V., Poutier, L., 2009. SIERRA: a new approach to atmospheric and topographic corrections for hyperspectral imagery. Remote Sensing of Environment 113, 1664-1677.

Lhermitte, S., Verbesselt, J., Verstraeten, W.W., Coppin, P., 2011. A comparison of time series similarity measures for classification and change detection of ecosystem dynamics. Remote Sensing of Environment 115, 3129-3152.

Liang, S., Fang, H., 2004. An improved atmospheric correction algorithm for hyperspectral remotely sensed imagery. IEEE Geoscience and Remote Sensing Letters 1, 112-117.

Liang, S., Fang, H., Chen, M., 2001. Atmospheric correction of Landsat ETM+ land surface imagery part I, methods. IEEE Transactions on Geoscience and Remote Sensing 39, 2490-2498.

Lillesand, T.M., Kiefer, R.W., Chipman, J.W., 2004. Remote Sensing and Image Interpretation, fifth ed. John Wiley \& Sons, Inc., New York.

Lu, D., Ge, H., He, S., Xu, A., Zhou, G., Du, H., 2008. Pixel-based Minnaert correction method for reducing topographic effects on a Landsat-7 ETM+ image. Photogrammetric Engineering and Remote Sensing 74, 1343-1350. 
Macovei, C., 2009. The wind as a climatic risk factor for the forestry fund of Suceava county. Present Environment and Sustainable Development 3, 275-286.

Markham, B. L., Barker, J. L., 1986. Landsat MSS and TM post-calibration dynamic ranges, exoatmospheric reflectances and at-satellite temperatures. Earth Observation Satellite Co., Lanham, MD, Landsat Tech. Note 1.

Meyer, P., Itten, K.L., Kellenberger, T., Sandmeier, S., Sandmeier, R., 1993. Radiometric corrections of topographically induced effects on Landsat TM data in alpine environment. Journal of Photogrammetry and Remote Sensing 48, 17-28.

Mihai, B., Savulescu, I., Sandric, I., 2007. Change detection analysis (1986-2002) of vegetation cover in Romania: a study of alpine, subalpine, and forest landscapes in the Lezer mountains, Southern Carpathians. Mountain Research and Development 27, 250-258.

Minnaert, N., 1941. The reciprocity principle in lunar photometry. Astrophysical Journal 93, 403-410.

Mitri, G.H., Gitas, I.Z., 2004. A performance evaluation of a burned area object-based classification model when applied to topographically and non-topographically corrected TM imagery. International Journal of Remote Sensing 25, 2863-2870.

Moran, M.S., Jackson, R.D., Slater, P.N., Teillet, P.M., 1992. Evaluation of simplified procedures for retrieval of land surface reflectance factors from satellite sensor output, Remote Sensing of Environment 41, 169-184.

Ono, A., Kajiwara, K., Honda, Y., 2007. Development of vegetation index using radiant spectra normalized by their arithmetic mean. Proceedings of $42^{\text {nd }}$ Conference of the Remote Sensing Society of Japan, Tokyo, Japan.

Pontius, R.G., 2000. Quantification error versus location error in comparison of categorical maps. Photogrammetric Engineering and Remote Sensing 66, 1011- 1016.

Rabus, B., Eineder, M., Roth, A., Bamler, R., 2003. The shuttle radar topography mission - a new class of digital elevation models acquired by spaceborne radar. Journal of Photogrammetry and Remote Sensing 57, 241- 262.

Rahman, H., Dedieu, G., 1994. SMAC: a simplified method for the atmospheric correction of satellite measurements in the solar spectrum. International Journal of Remote Sensing 15, 123-143.

Riaño, D., Chuvieco, E., Salas, F.J., Aguado, I., 2003. Assessment of different topographic corrections in Landsat TM data for mapping vegetation types. IEEE Transactions on Geoscience and Remote Sensing 41, 1056-1061.

Richter, R., 1996. Atmospheric correction of satellite data with haze removal including a haze/clear transition region. Computers and Geosciences 2, 675-681.

Richter, R., 1997. Correction of atmospheric and topographic effects for high spatial resolution satellite imagery. International Journal of Remote Sensing 18, 1099-1111.

Richter, R., 1998. Correction of satellite imagery over mountainous terrain. Applied Optics 37, 40044015. 
Richter, R., Kellenberger, T., Kaufmann, H., 2009. Comparison of topographic correction methods. Remote Sensing 1, 184-196.

Richter, R., Schläpfer, D., 2002. Geo-atmospheric processing of airborne imaging spectrometry data. Part 2: atmospheric/topographic correction. International Journal of Remote Sensing 23, 2631-2649.

Richter, R., Schläpfer, D., 2011. Atmospheric/topographic correction for satellite imagery. ATCOR 2/3 User Guide. Version 8.0.2.

Rosenfield, G. H., Fitzpatrick-Lins, K., 1986. A coefficient of agreement as a measure of thematic classification accuracy. Photogrammetric Engineering and Remote Sensing 52, 223-227.

Sandmeier, S., Itten, K.I., 1997. A physically-based model to correct atmospheric and illumination effects in optical satellite data of rugged terrain. IEEE Transactions on Geoscience and Remote Sensing 35, 708-717.

Schroeder, T.A., Cohen, W.B., Song, C., Canty, M.J., Yang, Z., 2006. Radiometric correction of multitemporal Landsat data for characterization of early successional forest patterns in western Oregon. Remote Sensing of Environment 103, 16-26.

Singh, S., Sharma, J.K., Mishra, V.D., 2011. Comparison of different topographic correction methods using AWiFS satellite data. International Journal of Advanced Engineering Sciences and Technologies 7, 103-109.

Slater, J.A., Garvey, G., Johnston, C., Haase, J., Heady, B., Kroenung, G., Little, J., 2006. The SRTM data finishing process and products. Photogrammetric Engineering and Remote Sensing 72, 237-247.

Smits, P. C., Dellepiane, S. G., Schowengerdt, R. A., 1999. Quality assessment of image classification algorithms for land-cover mapping: a review and proposal for a cost-based approach. International Journal of Remote Sensing 20, 1461-1486.

Smith, G.M., Milton, E.J., 1999. The use of the empirical line method to calibrate remotely sensed data to reflectance. International Journal of Remote Sensing 20, 2653-2662.

Smith, J.A., Lin, T.L., Ranson, K.J., 1980. The Lambertian assumption and Landsat data. Photogrammetric Engineering and Remote Sensing 46, 1183-1189.

Soenen, S.A., Peddle, D.R., Coburn, C.A., Hall, R.J., Hall, F.G., 2008. Improved topographic correction of forest image data using a 3-D canopy reflectance model in multiple forward mode. International Journal of Remote Sensing 29, 1007-1027.

Song, C, Woodcock, C.E., Seto, K.C., Lenney, M.P., Macomber, S.A., 2001. Classification and change detection using Landsat TM data: when and how to correct atmospheric effects? Remote Sensing of Environment 75, 230-244.

Sriwongsitanon, N., Surakit, K., Thianpopirug, S., 2011. Influence of atmospheric correction and number of sampling points on the accuracy of water clarity assessment using remote sensing application. Journal of Hydrology 401, 203-220.

Teillet, P.M., Guindon, B., Goodenough, D.G., 1982. On the slope-aspect correction of multispectral scanner data. Canadian Journal of Remote Sensing 8, 84-106. 
Turk, G., 1979. GT index: a measure of the success of prediction. Remote Sensing of Environment 8, 75- 86 .

UN-ECE/FAO, 2000. Forest Resources of Europe, CIS, North America, Australia, Japan and New Zealand (industrialized temperate/boreal countries). UN-ECE/FAO Contribution to the Global Forest Resources Assessment 2000. Geneva Timber and Forest Study Papers, No. 17, United Nations, New York and Geneva.

Van Ede, R., 2004. Destriping and geometric correction of an ASTER Level 1A Image, Thesis, Utrecht University, Utrecht, the Netherlands.

Vermote, E.F., Tanré, E., Deuzé, J.L., Herman, M., Morcrette, J.J., 1997. Second Simulation of the 677 Satellite Signal in the Solar Spectrum. An Overview. IEEE Transactions Geoscience Remote Sensing 35, 675-686.

Veraverbeke, S., Verstraeten W.W., Lhermitte, S., Goossens, R., 2010. Illumination effects on the differenced Normalized Burn Ratio's optimality for assessing fire severity. International Journal of Applied Earth Observation and Geoinformation 12, 60-70.

Veraverbeke, S., Lhermitte, S., Verstraeten, W.W., Goossens, R., 2011. A time integrated MODIS burn severity assessment using the multi-temporal differenced Normalized Burn Ratio (dNBRMT). International Journal of Applied Earth Observation and Geoinformation 13, 52-58.

Vicente-Serrano, S.M., Pérez-Cabello, F., Lasanta, T., 2008. Assessment of radiometric correction techniques in analyzing vegetation variability and change using time series of Landsat images. Remote Sensing of Environment 112, 3916-3934.

Vincini, M., Frazzi, E., 2003. Multitemporal evaluation of topographic normalization methods on deciduous forest TM data. IEEE Transactions on Geoscience and Remote Sensing 41, 2586-2590.

Wen, J., Liu, Q., Liu, Q., Xiao, Q., Li, X. , 2009. Parametrized BRDF for atmospheric and topographic correction and albedo estimation in Jiangxi rugged terrain, China. International Journal of Remote Sensing 30, 2875-2896.

Wu, J., Bauer, M.E., Wang, D., Manson, S., 2008. A comparison of illumination geometry-based methods for topographic correction of QuickBird images of an undulant area. ISPRS Journal of Photogrammetry and Remote Sensing 63, 223-236.

Zhang, W., Gao, Y., 2011. Topographic correction algorithm for remotely sensed data accounting for indirect irradiance. International Journal of Remote Sensing 32, 1807-1824.

Zhang, Z., De Wulf, R.R., Van Coillie, F.M.B., Verbeke, L.P.C., De Clercq, E.M., Ou, X., 2011. Influence of different topographic correction strategies on mountain vegetation classification accuracy in the Lancang Watershed, China. Journal of applied Remote Sensing 5, 1-21.

Zhao, W., Tamura, M., Takahashi, H., 2000. Atmospheric and spectral corrections for estimating surface albedo from satellite data using $6 S$ code. Remote Sensing of Environment 76, 202-212. 
5 (b)

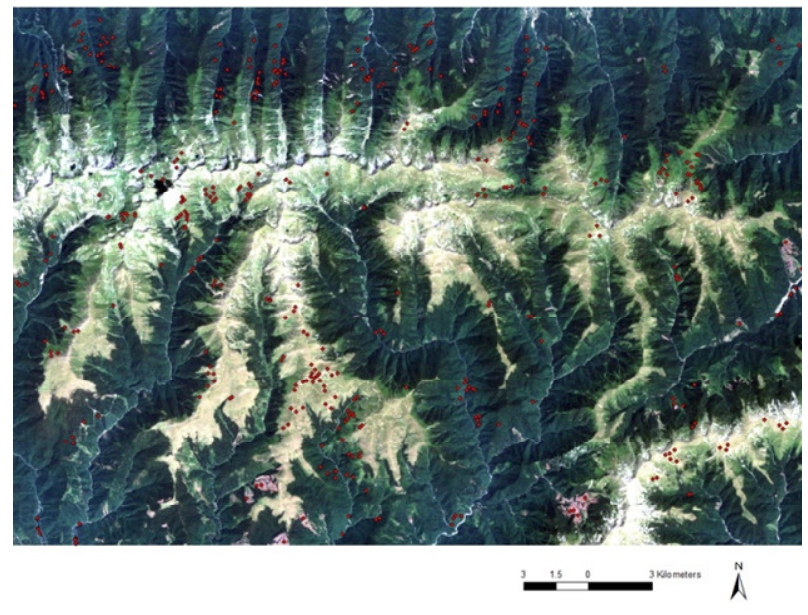

(a)

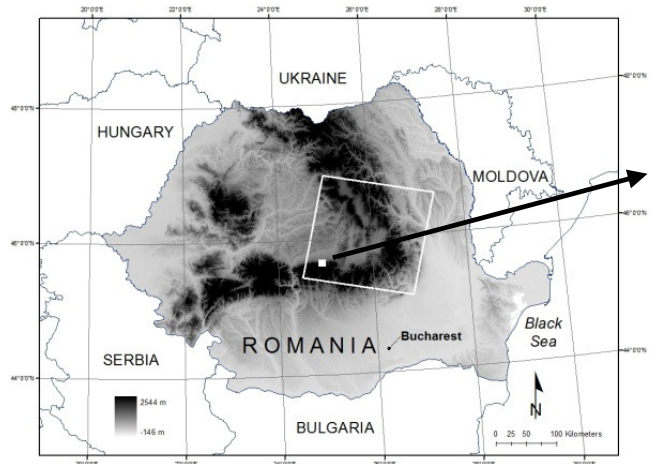

Fig. 1. (a) Location of the study area in Romania: the white-outlined rectangle delineates the Landsat image, the solid white rectangle is the study area. (b) True color composite image (RGB: band 3, 2 and 1) of the study area: the dots indicate the registered reference points. (available in color online)

(c)
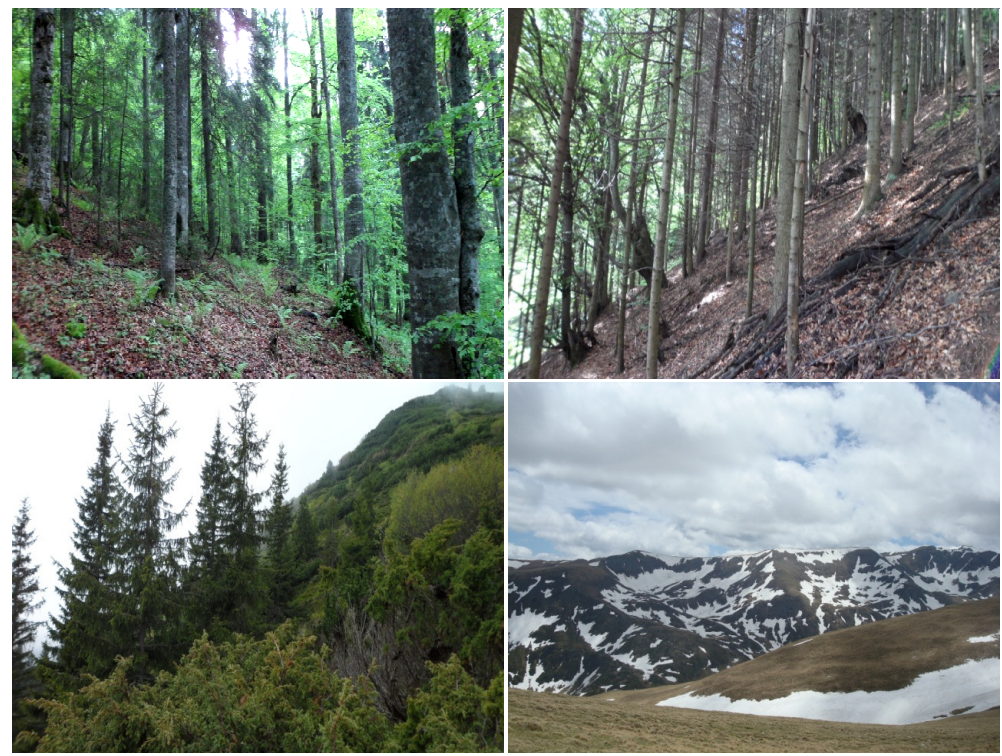

(b)

(d)

Fig. 2. (a) Foothill zone $(1,020 \mathrm{~m})$ with mixed and broadleaved forests. (b) Mountain zone $(1,640 \mathrm{~m})$ with coniferous forests. (c) Mountain zone $(2,050 \mathrm{~m})$ with small vegetation. (d) Alpine zone $(2,360 \mathrm{~m})$ above the tree line with grasses. (available in color online) 


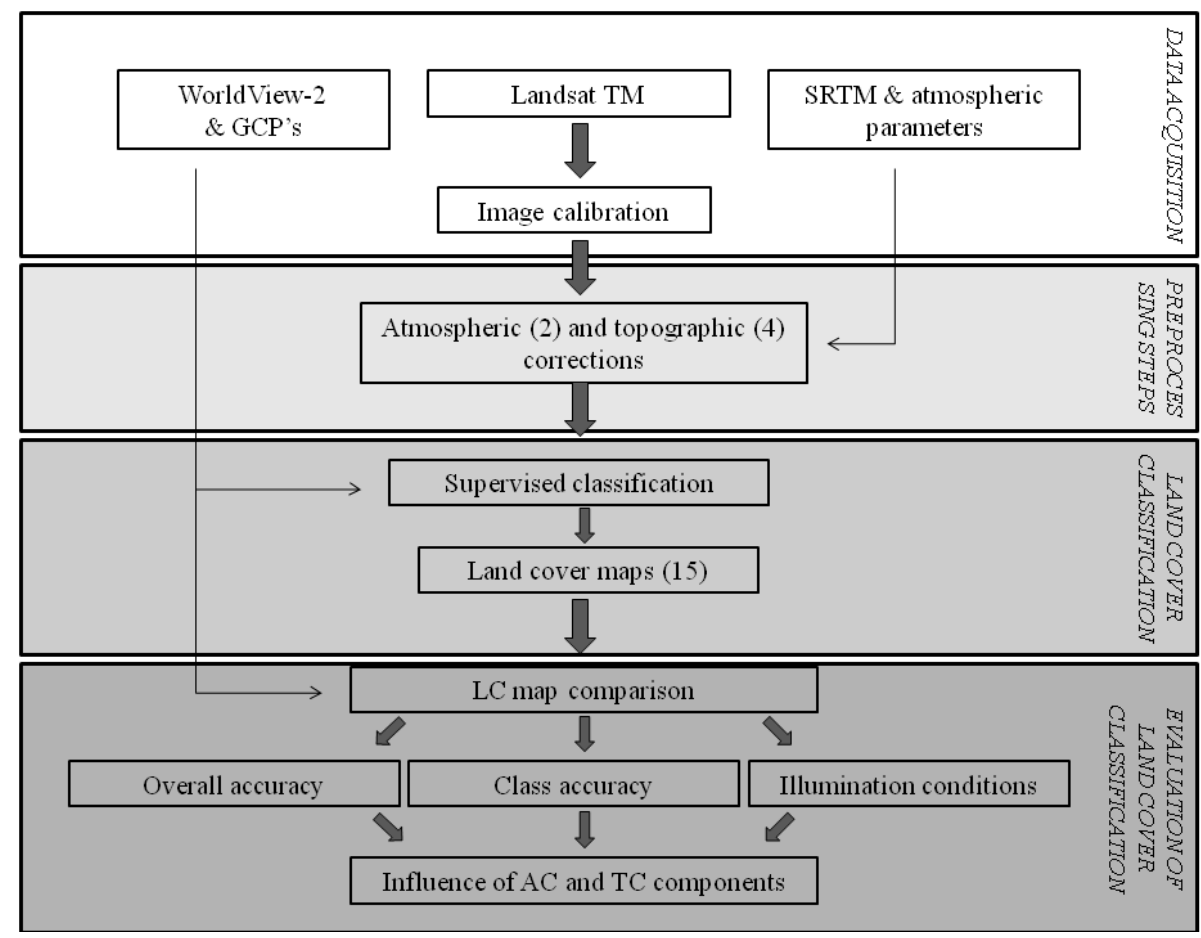

Fig. 3. Overview of the methodology: data acquisition, preprocessing steps, land cover classification and evaluation of the land cover classification.

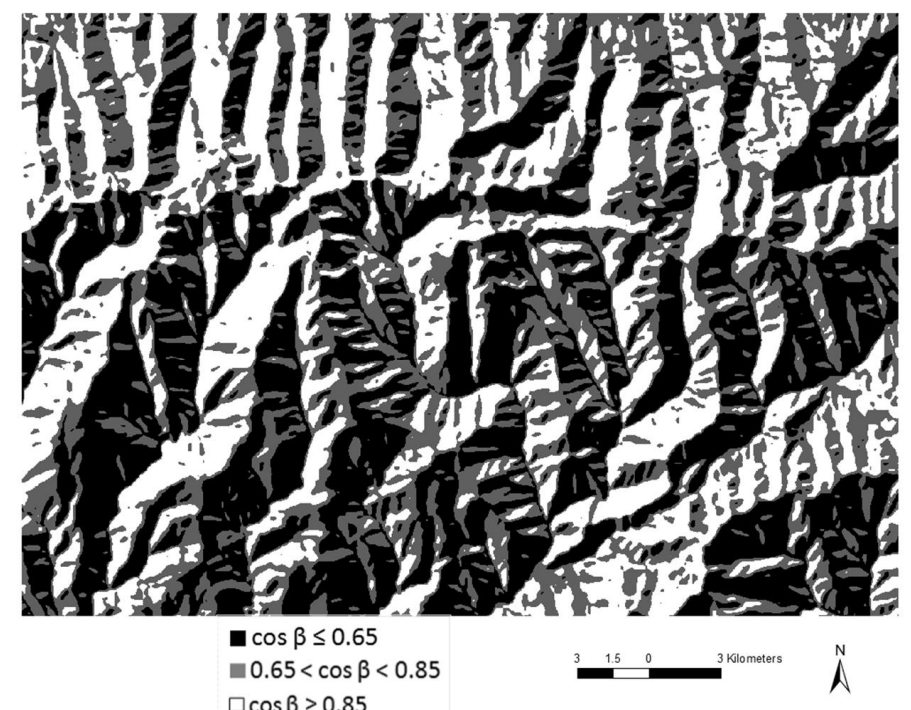

Fig. 4. The study area divided in three illumination zones: black is the low illumination zone [ $\cos \theta \leq 0.65]$, gray is moderate illumination $[0.65<\cos \theta<0.85]$ and the high illumination zone is indicated in white $[\cos B \geq 0.85]$. 

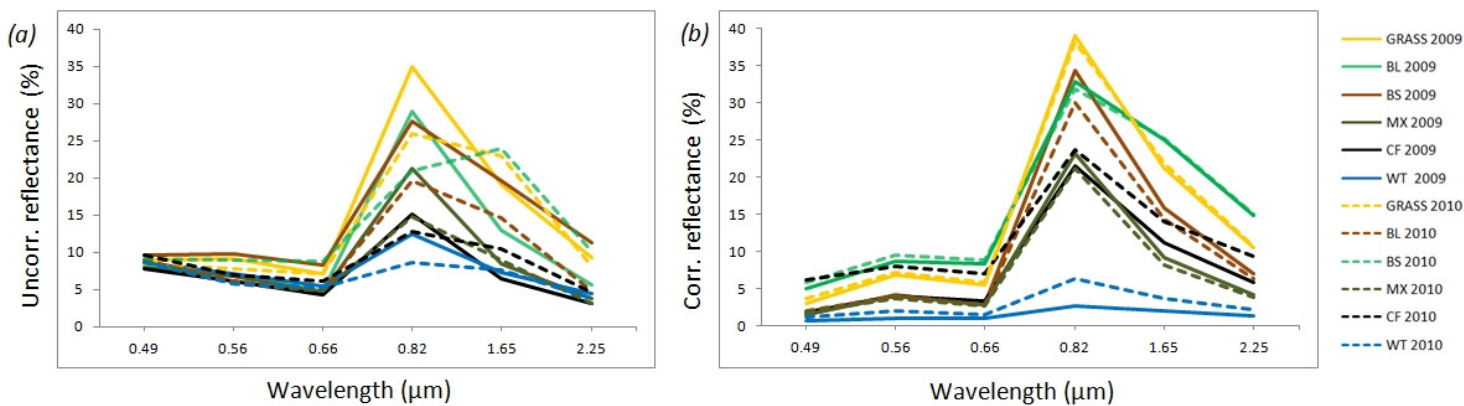

Fig. 5. (a) Average reflectance values per wavelength (band) and land cover type for the uncorrected images of 2009 (solid line) and 2010 (dashed line). (b) Average values for the most advanced method (TF-PBM) of 2009 (solid line) and 2010 (dashed line). (available in color online)

Full validation set $\square$ Difference subset

Fig. 6. Average kappa coefficients between the 2009 and 2010 images using the full validation set (black) or difference subset (white) of the 15 combinations of corrections. The range of classification accuracies between both dates is shown through the whiskers on the bars. 

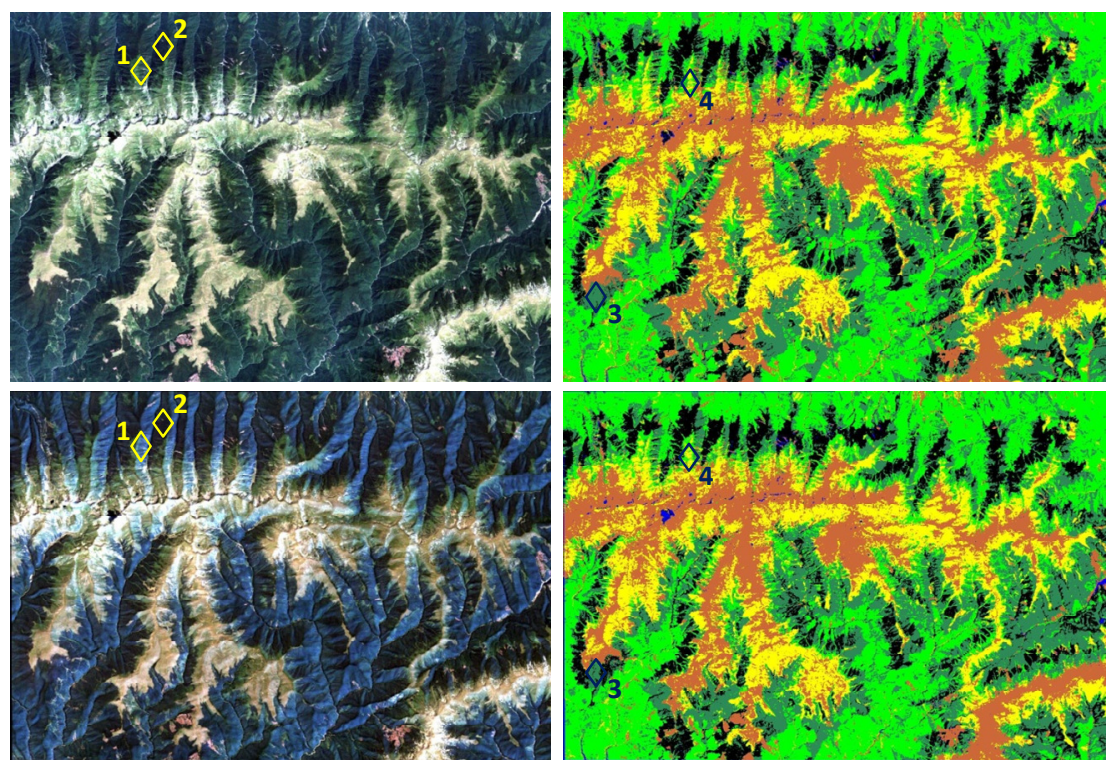

(b)
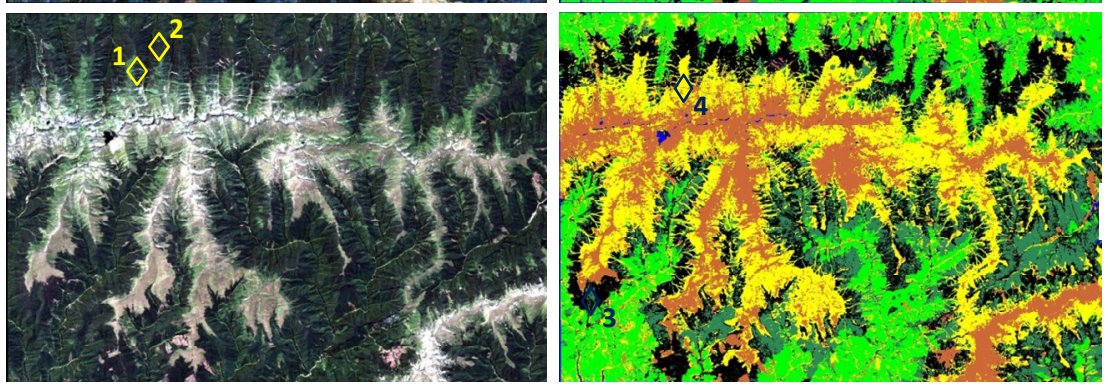

$$
\begin{aligned}
& \text { Bare soil } \\
& \text { BL forest } \\
& \text { QCF forest } \\
& \text { Grass } \\
& \text { GX forest } \\
& \text { B Water }
\end{aligned}
$$

Fig. 7. True color composite (RGB: band 3, 2 and 1) and ML classification of the 2009 image with a linear stretching: (a) no AC or TC with implementation of the GCP's; (b) TF with cosine correction and (c) TF with PBC correction. 


\begin{tabular}{|c|c|c|c|c|c|c|}
\hline & BS & $B L$ & CF & $\mathrm{MX}$ & GRASS & WT \\
\hline GLOBAL & - 0.03 & $\cdot 0.00$ & 0.09 & 0.09 & - 0.01 & $\cdot 0.00$ \\
\hline PBM_TF & 0.04 & - 0.02 & 0.17 & 0.18 & - 0.01 & $\cdot 0.00$ \\
\hline PBM_DOS & 0.09 & - 0.02 & 0.19 & 0.06 & - 0.01 & .0 .00 \\
\hline PBM_NoAC & - 0.02 & - 0.02 & 0.13 & 0.08 & - 0.01 & 0.00 \\
\hline PBC_TF & 0.04 & 0.03 & 0.14 & 0.14 & - 0.01 & - 0.00 \\
\hline PBC_DOS & 0.09 & - 0.02 & 0.12 & 0.16 & 0.01 & - 0.01 \\
\hline PBC_NoAC & - 0.02 & - 0.02 & 0.12 & 0.13 & - 0.01 & 0.00 \\
\hline Cosine_TF & 0.06 & - 0.02 & 0.08 & 0.07 & - 0.01 & 0.02 \\
\hline Cosine_DOS & 0.06 & - 0.01 & 0.05 & 0.02 & 0.01 & 0.00 \\
\hline Cosine_NoAC & - 0.01 & $\cdot 0.00$ & 0.04 & 0.00 & - 0.01 & $.0,00$ \\
\hline Bandratio_TF & 0.04 & 0.00 & 0.10 & 0,18 & 0.00 & .0 .00 \\
\hline Bandratio_DOS & 0.05 & 0.06 & - 0.03 & 0.07 & 0.06 & - 0.01 \\
\hline Bandratio_NoAC & - 0.01 & 0.00 & 0.10 & 0.08 & $\cdot 0.00$ & - 0.00 \\
\hline NoTC_TF & 0.03 & 0.06 & 0.04 & 0.02 & 0.03 & - 0.01 \\
\hline NOTC_DOS & 0.03 & 0.04 & 0.08 & & 0.12 & 0.00 \\
\hline
\end{tabular}

Fig. 8. Average 2009-2010 $\delta$ kappa values per class between uncorrected and corrected image using the full validation set for the 14 combinations of corrections and a global value per class over the 14 combinations of corrections. The size of the bubble represents the average 2009-2010 $\delta$ kappa value. A red color represents a negative $\delta$ kappa value and a blue color a positive $\delta$ kappa value. $\mathrm{BS}=$ bare soil; $\mathrm{BL}=$ broadleaved forest; $\mathrm{CF}=$ coniferous forest; $\mathrm{MF}=$ mixed forest; $\mathrm{GRASS}=$ grassland; $\mathrm{WT}=$ water. (available in color online)

\begin{tabular}{|c|c|c|c|c|c|c|}
\hline & BS & $B L$ & CF & $\mathrm{MX}$ & GRASS & WT \\
\hline GLOBAL & - 0.01 & $\cdot 0.00$ & & 0.10 & - 0.01 & - 0.01 \\
\hline PBM_TF & - 0.01 & - 0.03 & & 0.20 & - 0.01 & 0.00 \\
\hline PBM_DOS & 0.09 & - 0.02 & & 0.08 & - 0.02 & $\cdot 0.00$ \\
\hline PBM_NoAC & - 0.03 & - 0.02 & 23 & 0.09 & - 0.01 & - 0.01 \\
\hline PBC_TF & - 0.02 & - 0.02 & 30 & 0.15 & - 0.02 & - 0.01 \\
\hline PBC_DOS & - 0.01 & - 0.02 & 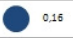 & 0.16 & - 0.04 & $.0,00$ \\
\hline PBC_NoAC & - 0.05 & - 0.02 & 0.12 & 0.13 & - 0.02 & 0.00 \\
\hline Cosine_TF & 0.07 & - 0.02 & & 0.09 & - 0.02 & - 0.02 \\
\hline Cosine_DOS & 0.06 & $\bullet 0.01$ & & 0.05 & $\cdot 0.01$ & $\cdot 0.00$ \\
\hline Cosine_NoAC & - 0.02 & - 0.04 & & - 0.02 & - 0.01 & . 0,00 \\
\hline Bandratio_TF & 0.05 & -0.02 & 0.19 & 0.09 & - 0.03 & . 0.00 \\
\hline Bandratio_DOS & $\bullet 0.03$ & -0.02 & & 0.07 & $\bullet 0.03$ & - 0.01 \\
\hline Bandratio_NoAC & - 0.02 & - 0.03 & & 0.08 & - 0.02 & - 0.01 \\
\hline NoTC_TF & - 0.03 & 0.08 & 0.23 & -0.02 & -0.02 & $\cdot 0,01$ \\
\hline NoTC_DOS & 0.05 & - 0.04 & 0.17 & 0.10 & 0.09 & - 0.04 \\
\hline
\end{tabular}

Fig. 9. Average 2009-2010 $\delta$ kappa values per class between uncorrected and corrected image using the validation subset for the 14 combinations of corrections and a global value per class over the 14 combinations of corrections. The size of the bubble represents the average 2009-2010 $\delta$ kappa value. A red color represents a negative $\delta$ kappa value and a blue color a positive $\delta$ kappa value. $\mathrm{BS}=$ bare soil; $\mathrm{BL}=$ broadleaved forest; $\mathrm{CF}=$ coniferous forest; $\mathrm{MF}=$ mixed forest; $\mathrm{GRASS}=$ grassland; $\mathrm{WT}=$ water. (available in color online) 


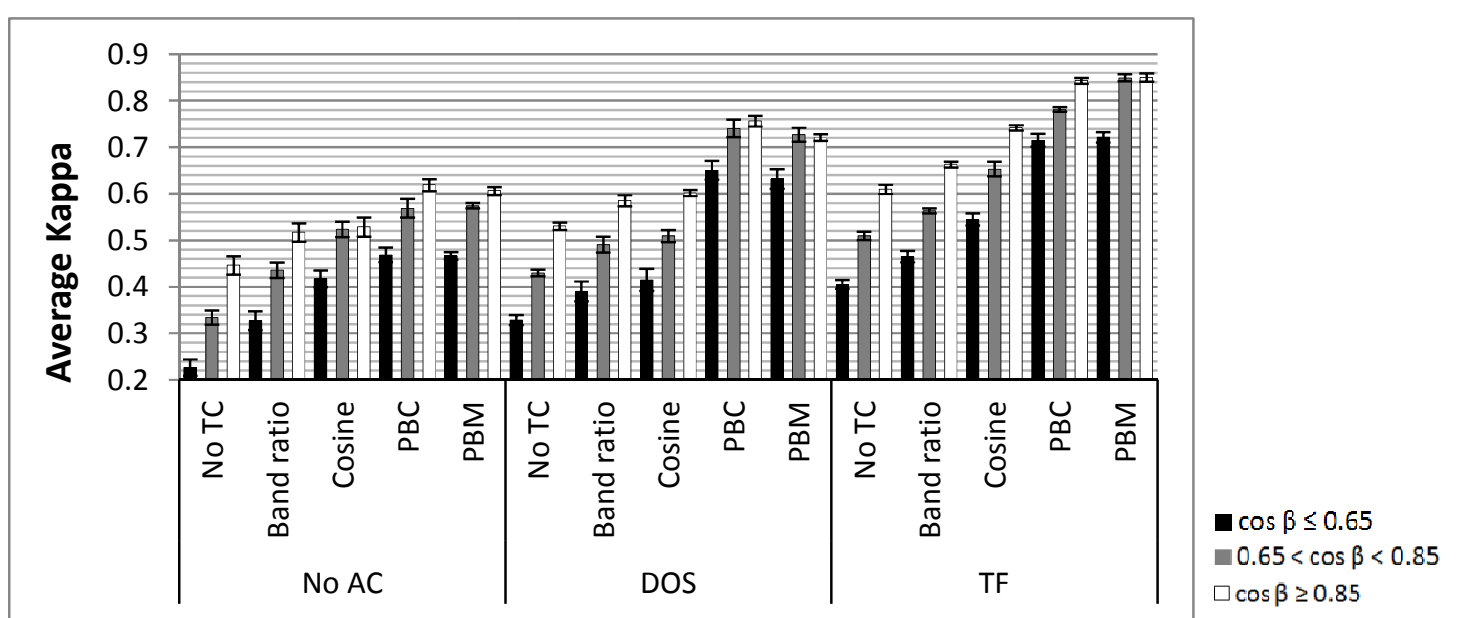

Fig. 10. Average kappa coefficients between the 2009 and 2010 images using the 15 combinations of corrections for three different illumination characteristics (black represents the low illumination zone, gray stands for the moderate illumination zone and white is the high illumination zone). The range of classification accuracies between both dates is shown through the whiskers on the bars. 
Table 1

Type, correction, reference and abbreviation of AC, TC and integrated (int.) or coupled methods.

\begin{tabular}{|c|c|c|c|}
\hline Type & Correction & Reference & Abbreviation \\
\hline \multirow[t]{11}{*}{ AC } & DOS & Chavez, 1996 & DOS is the dark object subtraction method \\
\hline & Empirical line & Smith and Milton, 1999 & \\
\hline & LOWTRAN-7 & Kneizys et al., 1988 & LOWTRAN is low resolution atmospheric transmission \\
\hline & ATCOR2 & Richter, 1996 & ATCOR2 is an acronym for atmospheric correction (AC) \\
\hline & $6 \mathrm{~S}$ & $\begin{array}{l}\text { Sriwongsitanon et al., 2011; Vermote et al., } \\
\text { 1997; Zhao et al., 2000; }\end{array}$ & $6 \mathrm{~S}$ is second simulation of a satellite signal in the solar spectrum \\
\hline & Inverse technique & Gilabert et al., 1994 & SMAC is a simplified method for AC \\
\hline & SMAC & Rahman and Dedieu, 1994 & \\
\hline & MODTRAN & Berk et al., 1998 & MODTRAN is moderate resolution atmospheric transmission \\
\hline & AC with look-up tables & Liang et al., 2001; Liang and Fang, 2004 & \\
\hline & Transmittance functions (TF) & Kobayashi and Sanga-Ngoie, 2008 & This method is the AC part of the integrated radiometric correction (IRC) \\
\hline & RTC's, image-based procedures and DOS & Moran et al., 1992 & RTC's are radiative transfer codes \\
\hline \multirow{19}{*}{ TC } & Minnaert & Bishop and Colby, 2002; Lu et al., 2008; & \\
\hline & & Minnaert, 1941; Smith et al., 1980 & \\
\hline & Cosine & Teillet et al., 1982 & \\
\hline & c & Bishop et al., 2003; Jensen, 1996; Meyer et al., & \\
\hline & & 1993; Teillet et al., 1982 & \\
\hline & Modified C-correction & Veraverbeke et al., 2011 & \\
\hline & Two stage topographic normalization & Civco, 1989 & \\
\hline & Minnaert with changing constant and correction based on empirical function & Ekstrand, 1996 & \\
\hline & SCS & Gu and Gillespie, 1998 & SCS is the sun-canopy-sensor topographic correction (TC) \\
\hline & C-Huang Wei & Huang et al., 2008 & \\
\hline & Band ratio, Minnaert, aspect partitioning and combinations of these corrections & Hale and Rock, 2003 & \\
\hline & Empirical, cosine, $C$ and Minnaert & Wu et al., 2008 & \\
\hline & Cosine, SCS, $b$ and VECA & Gao and Zhang, 2009 & VECA is the variable empirical coefficient algorithm \\
\hline & C, modified Minnaert and Gamma & Richter et al., 2009 & \\
\hline & Simplified normalization & Cuo et al., 2010 & \\
\hline & Cosine, C, Minnaert, modified Minnaert and empiric-statistic correction & Hantson and Chuvieco, 2011 & \\
\hline & Cosine, C, smooth C, SCS+C, C-Huang Wei and slope matching & Singh et al., 2011 & \\
\hline & Three-factor+C & Zhang and Gao, 2011 & \\
\hline & Cosine, Minnaert, C, SCS, two stage topo normalization and slope matching & Zhang et al., 2011 & \\
\hline \multirow{12}{*}{$\begin{array}{l}\text { Int. or } \\
\text { coupled }\end{array}$} & Inverse technique + band ratios & Conese et al., 1993 & \\
\hline & ATCOR2 + DEM [ATCOR3] & $\begin{array}{l}\text { Richter, 1997; Richter and Schäpfler, 2002; } \\
\text { Richter and Schäpfler, } 2011\end{array}$ & \\
\hline & $6 S+D E M$ & Sandmeier and Itten, 1997 & \\
\hline & DOS + Minnaert, $C$ and variation of $C$ & Riaño et al., 2003 & \\
\hline & DOS + cosine and SCS & Vincini and Frazzi, 2003 & \\
\hline & ATCOR2 + Minnaert & Mitri and Gitas, 2004 & \\
\hline & LOWTRAN-7 + Minnaert & Gitas and Devereux, 2006 & \\
\hline & MODTRAN + SCS & Huang et al., 2008 & \\
\hline & $T F+P B C[I R C]$ & Kobayashi and Sanga-Ngoie, 2008 & IRC is the integrated radiometric correction \\
\hline & DTA and $6 S+$ cosine and C & Vicente-Serrano et al., 2008 & DTA is the dark target approach \\
\hline & MODTRAN-4 + AMARTIS and SIERRA & Lenot et al., 2009 & $\begin{array}{l}\text { AMARTIS is advanced modeling of atmospheric radiative transfer for } \\
\text { inhomogeneous surfaces; SIERRA is spectral reflectance image extraction } \\
\text { from radiance with relief and AC }\end{array}$ \\
\hline & DOS + Minnaert and SCS & Gao and Zhang, 2009 & \\
\hline
\end{tabular}


Table 2

3 Reference, study area and land cover, classification method, AC and TC, and improvement in accuracy after correction.

\begin{tabular}{|c|c|c|c|c|}
\hline Reference & $\begin{array}{l}\text { Study area and } \\
\text { land cover (LC) }\end{array}$ & $\begin{array}{l}\text { Classification } \\
\text { method }\end{array}$ & $\mathrm{AC}$ and $\mathrm{TC}$ & $\begin{array}{l}\text { Improvement in } \\
\text { accuracy after } \\
\text { correction }\end{array}$ \\
\hline Conese et al., 1993 & Italy, all LC's & Supervised $\left(\mathrm{ML}^{1}\right)$ & $\begin{array}{l}\text { Inverse technique + topographic } \\
\text { normalization }\end{array}$ & $\begin{array}{l}\text { Kappa increase from } \\
0.56 \text { to } 0.62\end{array}$ \\
\hline Meyer et al., 1993 & $\begin{array}{l}\text { Switzerland, } \\
\text { (non)-forest }\end{array}$ & Not specified & No AC + statistical, Minnaert and C & $\begin{array}{l}\text { Overall accuracy (OA) } \\
\text { increase with } 10-30 \%\end{array}$ \\
\hline $\begin{array}{l}\text { Sandmeier and Itten, } \\
1997\end{array}$ & $\begin{array}{l}\text { Switzerland, all } \\
\text { LC's }\end{array}$ & Supervised (ML) & $6 S+D E M$ & $\begin{array}{l}\text { OA increase between } \\
1-7 \%\end{array}$ \\
\hline $\begin{array}{l}\text { Coburn and Roberts, } \\
2004\end{array}$ & $\begin{array}{l}\text { Canada, all } \\
\text { LC's }\end{array}$ & Supervised (ML) & $\begin{array}{l}\text { No } A C+\text { different statistical } \\
\text { texture measures }\end{array}$ & Not specified \\
\hline Hale and Rock, 2003 & USA, all LC's & Supervised (ML) & $\begin{array}{l}\text { No } A C+\text { band ratios, Minnaert, } \\
\text { aspect partitioning and } \\
\text { combinations of these corrections }\end{array}$ & $\begin{array}{l}\text { OA increase with } 4- \\
13 \%\end{array}$ \\
\hline Mitri and Gitas, 2004 & Greece, all LC's & $\begin{array}{l}\text { Fuzzy } \\
\text { classification }\end{array}$ & $\begin{array}{l}\text { ATCOR } 2+\text { multi-resolution } \\
\text { segmentation }\end{array}$ & OA of $98.85 \%$ \\
\hline $\begin{array}{l}\text { Blesius and Weirich, } \\
2005\end{array}$ & USA, all LC's & Supervised & No AC + Minnaert & No improvement \\
\hline $\begin{array}{l}\text { Gitas and Devereux, } \\
2006\end{array}$ & Greece, all LC's & Supervised (ML) & DOS + Minnaert & $\begin{array}{l}\text { OA increase of } \\
\text { maximum } 40 \%\end{array}$ \\
\hline Huang et al., 2008 & USA, all LC'S & $\begin{array}{l}\text { Unsupervised } \\
\left(\mathrm{SVM}^{2}\right)\end{array}$ & $\begin{array}{l}\text { MODTRAN + SCS and a revised } \\
\text { correction }\end{array}$ & $\begin{array}{l}\text { OA increase from } \\
85.5 \% \text { to } 89.1 \%\end{array}$ \\
\hline Soenen et al., 2008 & $\begin{array}{l}\text { Canada, all } \\
\text { LC's }\end{array}$ & Supervised (ML) & $\begin{array}{l}\text { Empirical line + cosine, } C \\
\text { Minnaert, statistical-empirical, } \\
\text { SCS, b, SCS+C and MFM-TOPO }\end{array}$ & $\begin{array}{l}\text { Class accuracy } \\
\text { increase between } 13- \\
62 \%\end{array}$ \\
\hline Gao and Zhang, 2009 & China, all LC's & Supervised (ML) & DOS + Minnaert and SCS & $\begin{array}{l}\text { OA increase from } \\
88.1 \% \text { to } 89.7 \%\end{array}$ \\
\hline Cuo et al., 2010 & $\begin{array}{l}\text { Thailand, all } \\
\text { LC's }\end{array}$ & Supervised & Simplified normalization & $\begin{array}{l}\text { OA from } 55 \% \text { to } 85 \% \\
\text { and } 51 \% \text { to } 91 \%\end{array}$ \\
\hline Zhang et al., 2011 & China, all LC's & $\begin{array}{l}\text { Unsupervised } \\
\text { (artificial neural } \\
\text { networks) }\end{array}$ & $\begin{array}{l}\text { No AC + cosine, Minnaert, C, SCS, } \\
\text { two stage normalization and slope } \\
\text { matching }\end{array}$ & No improvement \\
\hline
\end{tabular}

${ }^{1} \mathrm{ML}$ is the maximum likelihood classification algorithm

${ }^{2}$ SVM is the support vector machine method. 
Table 3

Overview of the three AC and five TC correction methods that were applied in this study (with equations and references).

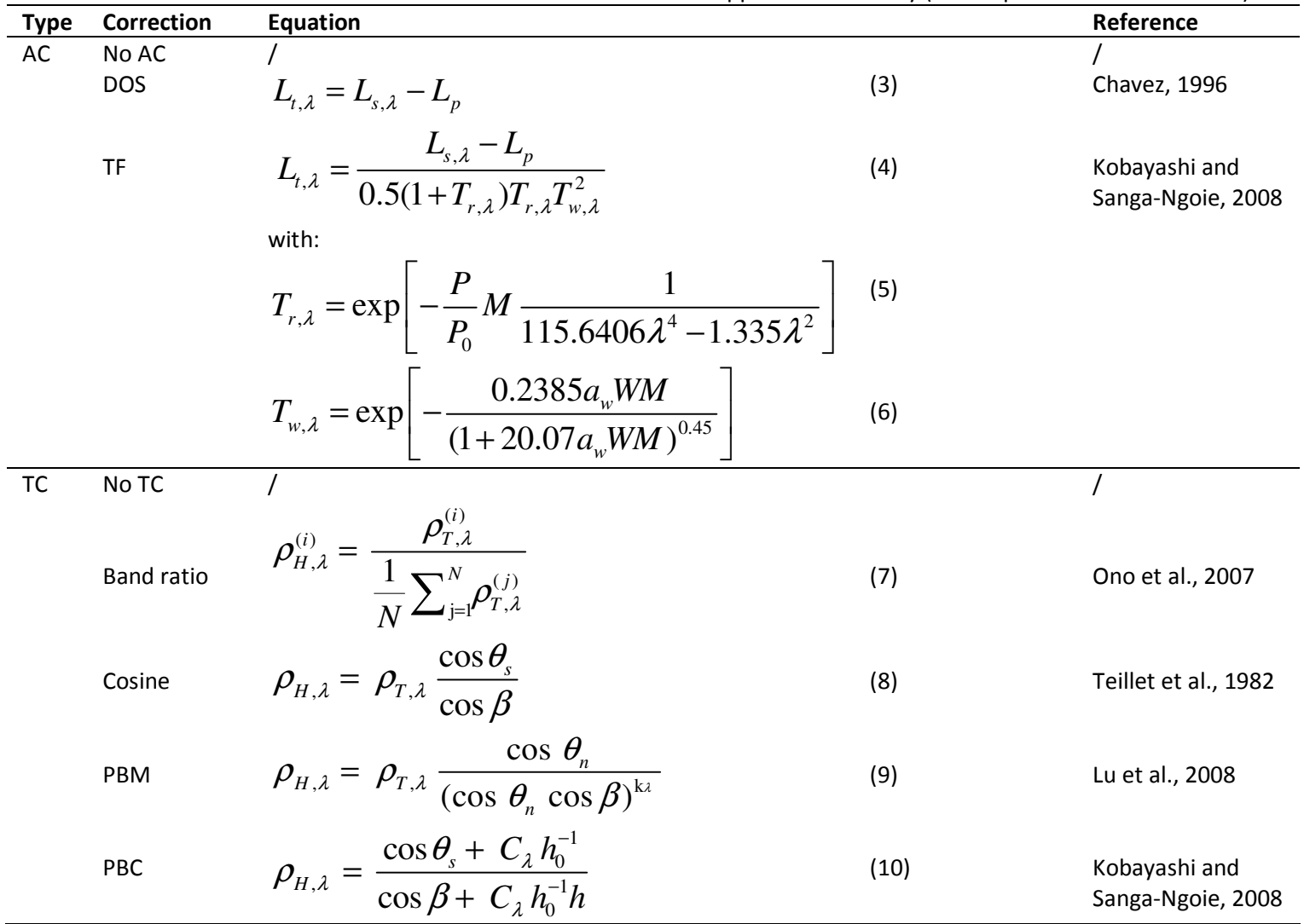

$L_{t, \lambda}$ is the corrected radiance value of the image, $L_{s, \lambda}$ is the uncorrected radiance value of the image and $L_{p}$ represents the minimum radiance of the uncorrected radiance values of the image. $T_{r, \lambda}$ is the Rayleigh scattering transmittance function and is function of sea-level atmospheric pressure $\left(P_{0} ;\right.$ in mbar), ambient atmospheric pressure $(P$; in mbar) and wavelength. The sea-level atmospheric pressure is 1,013 mbar. The relative air mass $M$ is calculated with the equation in the paper of Kobayashi and Sanga-Ngoie (2008) and implements the solar zenith angle. $T_{w, \lambda}$ is the water-vapor transmittance function and is calculated based on following parameters: precipitable water vapor $(W$; in $\mathrm{cm})$, relative air mass $(M)$ and water vapor absorption coefficients ( $a w$ ) given as a function of wavelength (Bird and Riordan, 1986). The value of $W$ is also obtained based on the acquisition date of the image and the geographic coordinates of the central point in the image. $\rho_{H, \lambda}$ stands for the normalized reflectance of a horizontal surface for a specific spectral band number $(N)$ and $\rho_{T, \lambda}$ for the observed reflectance on an inclined terrain. $B$ is the incident solar angle and $\cos B$ is the illumination parameter calculated by $\cos B=$ $\cos \vartheta_{s} \cos \vartheta_{n}+\sin \vartheta_{s} \sin \vartheta_{n} \cos \left(\phi_{t}-\phi_{a}\right)$. Where $\vartheta_{n}, \phi_{t}$ and $\phi_{a}$ denote the slope angle of the terrain, the aspect angle of the terrain and the solar azimuth angle, respectively. $k_{\lambda}$ is the slope of the regression between $x=\log \left(\cos \vartheta_{n} \cos B\right)$ and $y=$ $\log \left(\rho_{T, \lambda} \cos \vartheta_{n}\right)$ and is conducted for each slope group in order to develop the $\mathrm{k}$ value for each band corresponding to each slope group. Parameter $C_{\lambda}$ is the quotient of intercept $\left(b_{\lambda}\right)$ and slope $\left(m_{\lambda}\right)$ of the regression line between $x$ and $y$, the $h$ factor represents a topographic parameter deduced from the SRTM $\left[h=\left(1-\vartheta_{n}\right) / \pi\right]$ and the $h_{0}$-factor is an empirical parameter derived from the regression line between reflectance and $\cos B\left[h_{0}=\left(\pi+2 \vartheta_{s}\right) / 2 \pi\right]$. 
Land cover classes Code

Broadleaved forest $\mathrm{BL}$

Bare soil

Coniferous forest

BS

CF

Grassland

Mixed forest ${ }^{1}$

GRASS

$\mathrm{MX}$

WT

Water surface area (UN-ECE/FAO, 2000)

\begin{tabular}{|c|c|c|c|}
\hline & No AC - no TC & TF - cosine & TF - PBC \\
\hline Broadleaved forest & 26 & 29 & 19 \\
\hline Bare soil & 19 & 19 & 16 \\
\hline Coniferous forest & 12 & 11 & 20 \\
\hline Grassland & 15 & 16 & 29 \\
\hline Mixed forest & 27 & 24 & 15 \\
\hline Water surface & 1 & 1 & 1 \\
\hline
\end{tabular}

Dominant species

Carpinus betulus, Fagus sylvatica, Quercus petraea Quercus robur

/

Abies alba, Picea abies, Pinus mugo, Pinus sylestris

Betula pendula, Juglans sp., Prunus avium, Robinia Pseudoacacia, Salix sp., Sorbus sp., Tillia cordata /

for more than $75 \%$ of the tree crown

Table 5

43

44 